\title{
Distribution of plasma cells in normal rectal mucosa
}

\author{
RCF LEONARD, * ICM MACLENNAN† \\ From the Nuffield Department of Clinical Medicine, Oxford
}

SUMMARY In a survey of 36 histologically normal rectal biopsies, plasma cell counts were recorded at different depths of the lamina propria. The necessity of surveying the lamina propria at every level from the muscularis mucosae to the epithelium, in order to obtain an accurate estimate of plasma cell frequency is demonstrated. The relative accuracy of counting smaller areas of lamina propria is tested and the ratio of epithelium to lamina propria area established.

During the last $20 \mathrm{yr}$, various studies have attempted to apply the techniques of quantitative histology to the gut mucosa. ${ }^{1-5}$

The studies of Crabbé and coworkers were influential and gave detailed techniques for estimating absolute numbers of immunoglobulin-containing cells in various parts of the gut "interstitium." Crabbe concluded that the rectal lamina propria (based on five biopsies) contained around 183000 immunoglobulin-containing cells per cubic millimetre. ${ }^{12}$ These figures are derived from celldensities obtained from maximum-concentration areas, although the cell density varies substantially within the lamina.

The purpose of this study is to establish a method for counting that allows for this variation. While absolute concentrations of cells are not readily obtainable, relative concentrations can be obtained and are valuable for comparing disease groups. ${ }^{6-8}$ They may also be used for repeat studies on individual patients.

\section{Patients and methods}

Rectal biopsies were obtained at approximately $10 \mathrm{~cm}$ from two groups of patients: firstly, 18 individuals with minor bowel symptoms and secondly, 18 patients presenting with non-Hodgkin's lymphoma in whom the biopsy was part of a presentation assessment. The age distribution for the patients in this study was similar for both groups. Cell counts were performed only on samples that

*Present address: Sidney Farber Cancer Institute, Boston, Massachusetts, USA.

$\dagger$ Present address: Department of Immunology, University of Birmingham.

Accepted for publication 23 December 1981 were histologically normal by the criteria of Truelove and Richards. ${ }^{9}$

Each biopsy was placed epithelium uppermost on filter paper and immediately fixed in freshly acidified half-strength Zenker's solution. Samples were prepared for wax embedding by conventional techniques. Serial sections $(4 \mu \mathrm{m})$ were cut in a plane radial to the mucosa and adjacent sections stained using the PAP immunoperoxidase technique ${ }^{10}$ for kappa $(\kappa)$ and lambda $(\lambda)$ light chains respectively (materials supplied by Dakopatts, Copenhagen). Using this method, immunoglobulin-containing cells, morphologically recognisable as plasma cells, could be counted in serial sections, one for $\kappa$-positive cells, the next for $\lambda$-positive cells.

The tissue areas were measured by adopting the point-counting method of Weibel using the gridintercepts of a $1 \mathrm{~cm}$ graticule grid placed in one eyepiece of a standard Leitz binocular microscope. The $\times 40$ objective was used with $\times 10$ eyepieces.

Serial fields were examined travelling from epithelium (lumen) to muscularis mucosae until 1000 grid intercepts (points) had landed upon the lamina propria (Fig. 1). The amount of lamina required for survey was determined by reference to the work of Dunnill (MS Dunnill, personal communication 1981). ${ }^{11}$ In an attempt to allow for atrophy or oedema, points landing on the epithelium in each field were also recorded.

The amount of full-thickness lamina surveyed was assessed by recording the relative length of muscularis bordering upon the counted area. This was obtained by recording the number of vertical grid lines intercepting the upper border of the muscularis during the cell-counting (Fig. 1).

From these measurements it was possible to estimate (a) the total $\kappa$ cell count and the total $\lambda$ cell count per unit area of lamina propria; (b) the relative area of epithelium; (c) the cell counts at differ- 


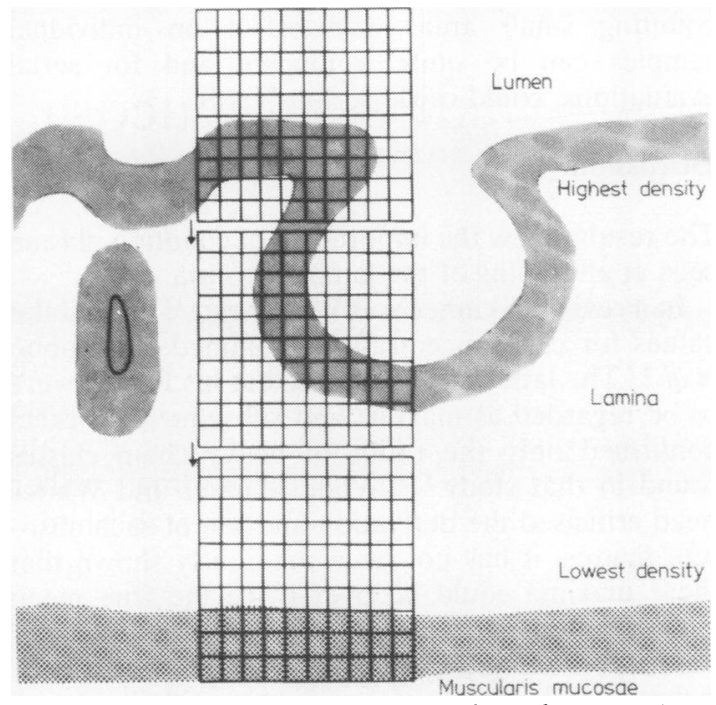

Fig. 1 Diagrammatic cross-section of rectal mucosa in a plane radial to the lumen. Each grid field covers approximately $1 / 4$ to $1 / 3$ depth of lamina at the chosen magnification. Muscularis length defined by vertical lines crossing its upper border. Epithelium and lamina propria areas defined by grid intercept (point) counts.

ent levels of the lamina propria. An index of the specimen quality was obtained by examining the length of muscularis mucosae as well as the relative area of epithelium.

\section{Results}

The results for the two groups of patients were not significantly different (Student's $t$ test) and they were therefore combined to give a single group of 36.

The number of fields required to reach 1000 grid intercepts of lamina propria varied from 18 to 30 with a mean of 24 . In four cases, between 800 and 950 points were scored because the countable area of biopsy was insufficient to produce 1000 intercepts. Figure 2 illustrates the relative density of plasma cells in the lamina propria adjacent to the epithelial border and in lamina adjacent to the muscularis mucosae. These figures were obtained by the aggregation of six fields in each region of the lamina. The mean count for each specimen is also shown.

The cell concentration in these two regions of lamina are markedly different, the cell density on average being about five times as great in the epithelial region of lamina as against the muscularis region.

The quality and orientation of the specimens was consistent and the scatters of the ratios of lamina to

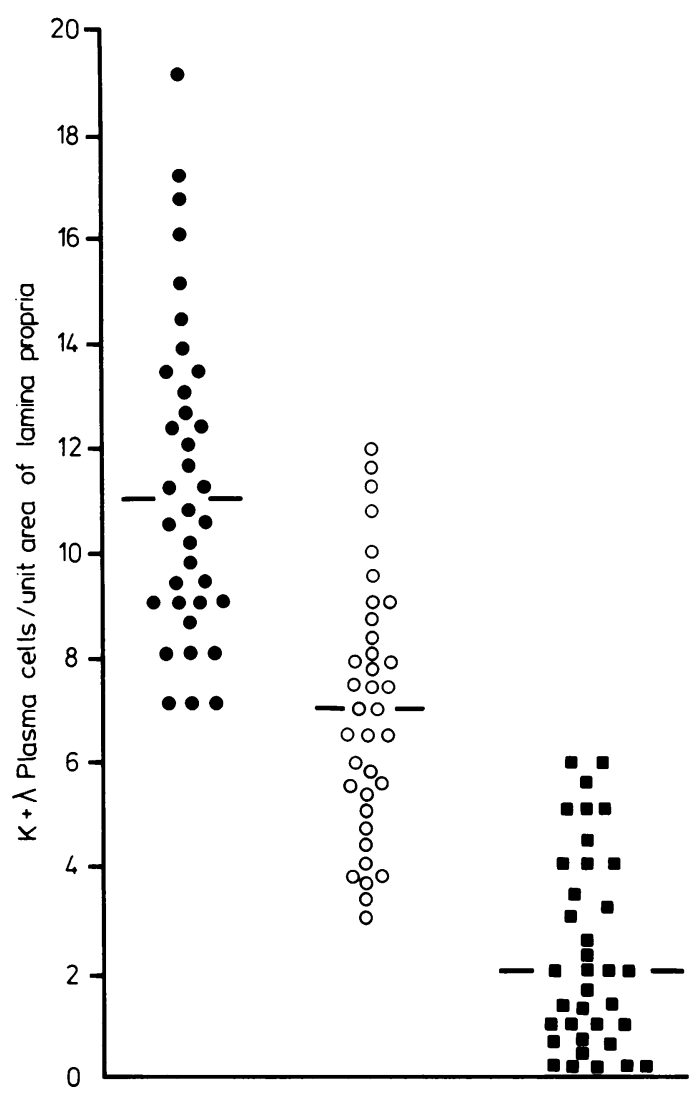

Fig. 2 Scatter graphs of plasma cell density in the lamina propria (expressed, to nearest whole number, as cells per 10 intercepts on lamina propria).

= in lamina propria bordering upon epithelium - that is, in tissue superficial to a point half way between the base of the crypts and the superficial surface of the muscularis mucosae

= in lamina propria bordering upon muscularis mucosae - that is, the tissue deep to a point midway between the base of the crypts and the superficial surface of the muscularis mucosae

$\mathrm{O}=$ average density in lamina propria.

[Figures are derived from six aggregated fields at each level whereas the average density is calculated from the whole (1000 point) area]. Horizontal bars equal medians.

epithelium area and of the relative lengths of muscularis mucosae surveyed are illustrated in Figs. 3a and $3 b$. The $\kappa: \lambda$ ratio of this population of patients is shown in Fig. 3c.

Because of the time-consuming nature of the technique, an attempt was made to evaluate the accuracy of counting approximately half (first 12 fields) of the recommended area of lamina propria. The results (from 14 individuals) are recorded in the Table. Whilst the results are broadly similar for 


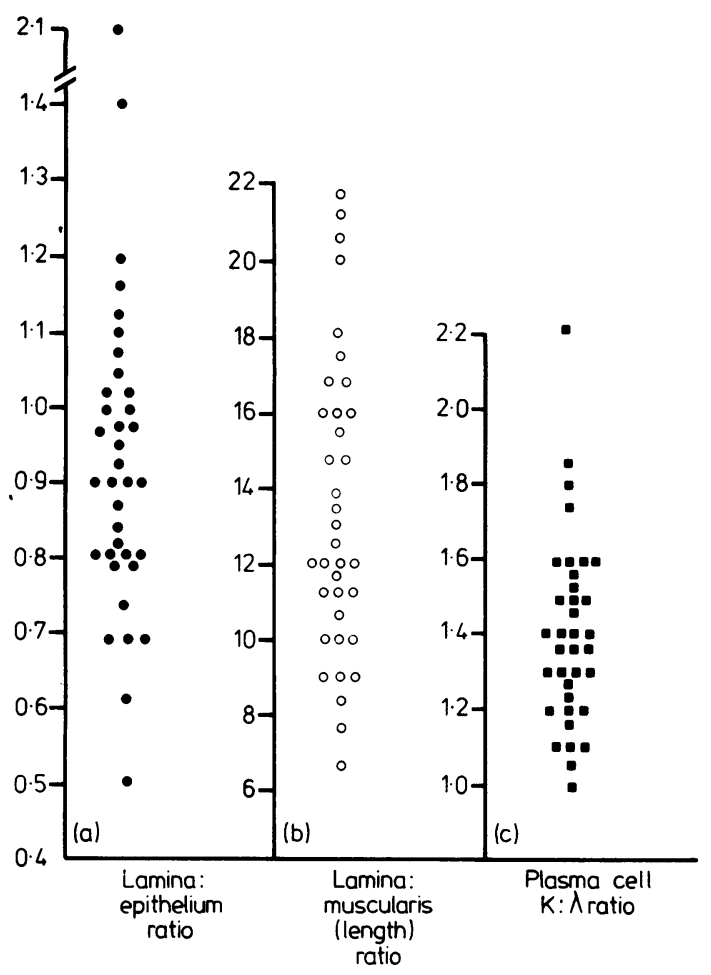

Fig. 3(a) Scattergraph (๑) showing variation in ratio of lamina area to epithelium area. (b) scattergraph $\bigcirc$ showing variation in specimen quality defined by relative length of muscularis mucosae bordering the counted area of lamina propria (grid intercepts on lamina devided by line intercepts on upper border of muscularis). (c) scattergraph (ם)

showing variation in $\kappa: \lambda$ cell ratio in the normal specimens. counting small areas, the effect on individual samples can be quite significant and for serial evaluations, could cause serious error.

\section{Discussion}

The results show the importance of counting plasma cells at all depths of the lamina propria.

In a review, Skinner and Whitehead, ${ }^{12}$ quoted the values for cell concentrations obtained by Crabbé et al. ${ }^{12}$ The latter clearly stated that his figures were to be regarded as maxima and subsequent workers confirmed only the ratios of heavy chain classes found in that study. ${ }^{3-5}$ While Skinner and Whitehead criticised the derivation and use of such absolute figures, it has not been previously shown that these maxima could be over twice the true mean concentration.

The point counting method was a reliable way of estimating the ratio of lamina to epithelium and there was little variation in the relative areas amongst specimens. The greater variability in muscularis length estimations is mainly due to specimen curling which gives a falsely low estimate of the length of muscularis surveyed. It has been suggested that muscularis area would be a good reference for quantitative models as it can be assumed that atrophy, hypertrophy, and oedema are less likely to affect this tissue than others in the mucosa. ${ }^{12}$ For the present study, estimating muscularis area by point counting proved unreliable as breaking of the muscle fibres was a common feature; length estimations, however, were less affected by this sort of artefact. It is difficult to avoid some curling of the specimen during preparation but placing the fresh specimen on stiff paper before fixation reduces this.

The use of PAP on fixed tissue for such studies has

Effect upon data of counting only a limited area (12 fields) of lamina propia

\begin{tabular}{|c|c|c|c|c|c|c|}
\hline \multirow[t]{2}{*}{ Patient } & \multicolumn{2}{|c|}{ Ratio of lamina:epithelium } & \multicolumn{2}{|c|}{ Plasma cell count per unit area lamina } & \multicolumn{2}{|l|}{$\kappa: \lambda$ ratio } \\
\hline & Full survey & Small survey & Full survey & Small survey & Full survey & Small survey \\
\hline $\begin{array}{r}1 \\
2 \\
3 \\
4 \\
5 \\
6 \\
7 \\
8 \\
9 \\
10 \\
11 \\
12 \\
13 \\
14\end{array}$ & $\begin{array}{l}0.78 \\
0.96 \\
1.16 \\
0.93 \\
0.97 \\
0.47 \\
1.03 \\
0.91 \\
1.11 \\
0.99 \\
1.12 \\
1.01 \\
0.75 \\
1.39\end{array}$ & $\begin{array}{l}0.77 \\
0.99 \\
1.10 \\
0.82 \\
0.95 \\
0.49 \\
1.05 \\
1.07 \\
1.09 \\
0.97 \\
1.17 \\
1.10 \\
0.81 \\
1.33\end{array}$ & $\begin{array}{l}4 \cdot 71 \\
7.80 \\
6 \cdot 50 \\
6.96 \\
7 \cdot 37 \\
8 \cdot 42 \\
6 \cdot 69 \\
6 \cdot 11 \\
5 \cdot 06 \\
5 \cdot 22 \\
6 \cdot 48 \\
3.76 \\
8 \cdot 62 \\
3.77\end{array}$ & $\begin{array}{l}4.92 \\
7.32 \\
6.49 \\
7.43 \\
7.92 \\
8.29 \\
5.93 \\
4.95 \\
4.86 \\
3.98 \\
6.00 \\
2 \cdot 10 \\
4.98 \\
4.14\end{array}$ & $\begin{array}{l}1.80 \\
1.34 \\
1.40 \\
1.09 \\
0.99 \\
1.05 \\
1.24 \\
1.44 \\
1.42 \\
1.38 \\
1.61 \\
1.52 \\
1.75 \\
1.81\end{array}$ & $\begin{array}{l}1.44 \\
1.36 \\
1.36 \\
1.01 \\
0.74 \\
0.94 \\
1.39 \\
1.49 \\
1.42 \\
1.84 \\
1.50 \\
1.59 \\
1.51 \\
2.00\end{array}$ \\
\hline
\end{tabular}

Full survey: area of lamina surveyed $950-1150$ grid intercepts.

Small survey: area of lamina surveyed 287 to 579 grid intercepts. 
the great advantage of clear morphology although fixation and tissue dehydration make it unreasonable to calculate the absolute plasma cell concentration in vivo. Other difficulties arise from variation in tissue thickness and differences in cell size.

This technique of studying gut plasma cells has already proved to be of value in recognising immunosuppression of secretory antibody, and light-chain isotype suppression in certain B cell neoplasia. ${ }^{13}$

The reduced area technique might be of value in comparing such disease groups. However, for accurate estimation of plasma cell concentration in serial samples, the full area (often whole biopsy) and depth of lamina propria should be surveyed.

The authors are indebted to Dr RI Vanhegan, Mrs Y Smart, Dr MS Dunnill, Dr WCD Richards and Dr $\mathrm{J}$ Piris for their assistance.

\section{References}

' Crabbé PA, Heremans JF. The distribution of immunoglobulincontaining cells along the human gastrointestinal tract. Gastroenterology 1966;51:305-16.

${ }^{2}$ Crabbé PA, Carbonara AO, Heremans JF. The normal human intestinal mucosa as a major source of plasma cells containing yA immunoglobulin. Lab Invest 1965;14:235-48.

${ }^{3}$ Gelzayd EA, Kraft SC, Fitch FW, Kirsner J. Distribution of immunoglobulins in human rectal mucosa. II. Ulcerative colitis and abnormal mucosá control subjects. Gastroenterology 1968;54:341-7.
4 Soltoft J. Immunoglobulin-containing cells in the jejunal mucosa and in ulcerative colitis and regional enteritis. Scand $J$ Gastroenterol 1969;4:353-60.

${ }^{5}$ Binder V. Cell density in lamina propria of the colon: a quantitative method applied to normal subjects and ulcerative colitis patients. Scand J Gastroenterol 1970;5:485-90.

' Skinner JM, Whitehead R. The plasma cells in inflammatory disease of the colon-a quantitative study. J Clin Pathol 1974;27:643-6.

' Skinner JM Whitehead R, Piris J. Argentaffin cells in ulcerative colitis. Gut 1971;12:636-8.

${ }^{8}$ Guix M, Skinner JM, Whitehead R. Measuring intraepithelial lymphocytes, surface area and volume of lamina propria in the jejunal mucosa of coeliac patients. Gut 1979;20:275-8.

9 Truelove SC, Richards WCD. Biopsy studies in ulcerative colitis. Br Med J 1956;i:1315-8.

${ }^{10}$ Burns J. Background staining and sensitivity of the unlabelled antibody enzyme (PAP) method. Comparison with the peroxidase-labelled antibody sandwich method using formalin-fixed paraffin-embedded material. Histochemistry 1975;43:291-4.

"Dunnill MS, Whitehead R. A method for quantitating small intestinal biopsy specimens. J Clin Pathol 1972;25:243-6.

${ }_{12}$ Skinner JM, Whitehead R. Morphological methods in the study of the gut immune system in man. J Clin Pathol 1976;29:564-8.

${ }^{13}$ Leonard RCF, MacLennan ICM, Smart Y, Vanhegan RI, Cuzick J, MRC Working Party for Leukaemia in Adults, Oxford Lymphoma Group. Light chain isotype-associated suppression of normal plasma cell numbers in patients with multiple myeloma. Int J Cancer 1979;24:385-93.

Requests for reprints to: Professor ICM MacLennan, Department of Immunology, The Medical School, University of Birmingham, Birmingham B15 2TJ, England. 